\title{
On predicator rules and indexicality
}

\author{
Sobre las reglas de predicador e indexicalidad
}

\author{
Clément Lion
}

University of Lille, France

clement_lion@orange.fr

DOI: https://doi.org/10.22370/rhv2019iss13pp18-33

Recibido: 02/07/2019. Aceptado: 14/08/2019

\begin{abstract}
We argue that no attempt of reducing meaning to a systematic set of rules, according to which the role of linguistic expressions is to be normatively defined, can be abstracted from an irreducibly decisional compound. By comparing Lorenzen's project of building an Ortho-language (Orthosprache) and Brandom's inferentialist take on meaning, we distinguish two ways of acknowledging this fact, while claiming that Lorenzen's take is more genuinely constructive, insofar as choices be thought of as genuine features of constructions. It brings into a new perspective the relation between dialogical constructivism and Brouwer's intuitionism. Finally, we bring up a philosophical argument for the claim that interaction rules should be indexed on players and on their choices, when providing deontic bases to semantics.
\end{abstract}

Keywords: Ortho-Language, predicator rules, inferentialism, choices, dialogic, semantics.

\section{Resumen}

Argumentamos que ningún intento de reducir el significado a un conjunto sistemático de reglas, según el cual el papel de las expresiones lingüísticas debe definirse normativamente, puede abstraerse de un compuesto irreductiblemente decisional. Comparando el proyecto de Lorenzen de construir un lenguaje ortodoxo (Orthosprache) con el enfoque inferencialista de Brandom sobre el significado, distinguimos aquí dos formas de reconocer este hecho. Afirmaremos entonces que el enfoque de Lorenzen es más genuinamente constructivo, en la medida en que las elecciones se consideran características genuinas de las 
construcciones. Esto nos llevará a una nueva perspectiva de la relación entre el constructivismo dialógico y el intuicionismo de Brouwer. De esta manera, presentamos un argumento filosófico para la afirmación de que las reglas de interacción deben indexarse en relación a los jugadores y sus elecciones, al proporcionar bases deónticas a la semántica.

Palabras clave: lenguaje ortodoxo, reglas de predicador, inferencialismo, elecciones, dialógica, semántica.

\section{Introduction}

It is nowadays widely accepted that the Augustinian picture of language - following Wittgenstein (1984)'s quotation of Confessiones I/8, which is intended at summing up the claim that words name objects - cannot provide a satisfying account of the way meaning is constituted. One alternate proposal to such a picture consists in thinking meaning as being immanent to the (correct) use of language, following Wittgenstein's alleged slogan, namely that "meaning is use". Inferentialism represents currently a research program whose aim is to give a semantic account of any part of language in terms of the way it contributes to carrying out inferences, to which a speaker (tacitly) commits himself when uttering a sentence. This research program stems partly from some of Sellars' insights in particular that "to grasp a concept is mastering its use", but it would be fair to say that, despite of some differences, it relies also to perspectives that were deployed within the frame of the so called Erlangen Constructivism. In Kamlah and Lorenzen (1996, 73), the meaning of a predicate is explicitly defined in terms of determinate relations that are associated to a set of tacit commitments a speaker is to be responsive for when speaking. Understanding the meaning of a predicate is nothing else than knowing which commitments one takes when uttering something and according to which rules these can be assessed. It corresponds thus closely to the "game of giving and asking for reason" (Brandom 2000, 165) whose practical mastery represents, Brandom says, what understanding the meaning of an utterance actually consists in, even though, as we will see, there might be crucial shades between the respective concepts of a predicator rule, in Lorenzen's terminology, and of an inferential relation. ${ }^{1}$

Now, that meaning be immanent to the use of language, in such a way that referring to be explained in terms of inferring does not preclude, of course, that the use of language be itself indexed on something extra-linguistic: the non-linguistic circumstances of statements are inferentially articulated to them, in so far as, by being confronted with certain perceptual contents, a speaker is committed to make (or, at least, not to make) determinate assertions. The source of the inferential normativity that relies non-linguistic circumstances to utterances is the self-constitution of a linguistic community as setting up

\footnotetext{
${ }^{1}$ According to Rahman et al. (2018, 268-271), the former should rather be conceived as a transition relation: it expresses a presupposition, which is not the same as a genuine inferential relation.
} 
the norms of meaningfulness (Brandom 1994, 119). In Brandom's view, adopting a (dynamic) system of rules depends thus on integrating a community for which these rules are holding good: it is thus a matter of going along the lines of a common institution. Hence, meaning relies to a normative fact, namely the fact that "one uses words this way". It does not mean that explicit rules can ever be stated once and for all, as representing the correct way of using words, but it means that any linguistic community regulates itself in such a way that the correctness of uses is dynamically laid down by the community itself and that being submitted to these norms of correctness presupposes entering into a community as a responsible speaker.

Now, let us observe that were there several different linguistic communities, submitted to different systems of rules, however there should be also a common principle of regulation. Ultimately, no local space of meaning — even taking the form of a whole historical community - may ever be considered as representing something else as a provisional degree of explicitness. In other words, the normative fact that consists in contingently belonging to a determined community should tend to be diluted in a normative universal realm, located beyond any factual anchoring of a concrete speaker. In Brandom's words:

Each one defines a different way of saying 'we', each kind of 'we'-saying defines a different community, and we find ourselves in many communities. This thought suggests that we think of ourselves in broadest terms as the ones who say 'we'. It points to the one great Community comprising members of all particular communities - the Community of those who say 'we' with and to someone, whether the members of those different particular communities recognize each other or not. (Brandom 1994, 4)

\section{Inferentialism and subjectivity}

If one assumes indeed an inferentialist perspective on meaning, and especially on the meaning of elementary propositions, then one must also assume that any use of a predicate should be normatively regulated, at least through the implicit preclusion of all possible incorrect moves involving it, out of a common (and ideally universal) space of use. Now, within the space which is thus negatively defined, an innumerable quantity of moves are still permitted. Each of those participates to specify the stitches of a common web of meaningful statements, that represent potential discursive positions, insofar as they enable one to keep the line against specification requests, possibly addressed to any utterer taking part of it. This is certainly the way scientific language is regulating its own use, by trials and errors.

Someone who would like to go on speaking out of this regulative process will be soon disqualified as talking non-sense, or at least as talking alone: he will locate himself out of the common linguistic space as it is normatively instituted. It does not mean at all that no singular creation of meaning be ever thinkable: it only means that once created, then 
meaning has to be regulated through collective use, so that only these statements, that are conservative over other already well accepted statements in their most far implications and presuppositions - unless they indicate explicit ways to transform some of these well accepted positions into more efficient ones-, will be able to keep on going in the public space of meaning. Accordingly, any meaning assumption is to be thought of as being essentially communicable and potentially strengthened through the process of communication.

Therefore, any strictly subjective position should be thought of as tending to dilution in a public space of assessment. In other words, the meaning of concepts is to be thought of as a (universally) normative feature (Brandom 2000, 29). For several potential utterers, understanding one and the same concept in different ways would be thus only a matter of being more or less close to the grasp of the whole web of inferential relations within which it is to be located. There are several degrees of mastery: no conflicting ways of rightly grasping a concept may be sustained on the long run, unless its meaning is still on the way to be determinate. One may factually grasp only a small part of the relevant inferential relations, according to the anchoring of his life within a particular context of use, but the very norm according to which his own speech is to be assessed is ultimately beyond this factual grasp. Accordingly, one may understand incorrectly the meaning of his own utterances: subjectivity is not the right location of meaning and no one is entitled to claim that his own understanding be more accurate than the public assessment of it, at least not without a rightly defensible justification, eventually detachable from him.

If the meaning of utterances depends on mastering their correct use, then assessing this correctness presupposes making the rules explicit, according to which these utterances play a role within concrete practices. Now, the process of making them explicit necessarily depends on choosing a device through which projecting concrete uses on a (formalized) means of expression of the accorded rules becomes possible, in such a way that the correctness of an inferential relation can be communally assessed, by referring to determinate criteria one has agreed on. Hence, meaning has to be artificially identified with an ideal set of norms enabling one to give an account of every compounds of meaningful utterances.

In this extent, even though inferentialism is explicitly connected with Wittgenstein's second philosophy, it would be misleading to reduce the latter to the former, because Wittgenstein explicitly rejects any claim of possessing such a unified device to approach meaning (Wittgenstein 1984, 250). Beyond his admittance of given forms of life on which every possible uses of signs are to be anchored, a further (decisional) step has to be carried out in order to build a systematic approach such as inferentialism aims to be. Indeed, it presupposes admitting a certain way of reconstruction as reliable for clarifying any meaning. Namely, inferentialism is based on linking meaning to argumentative justification, and therefore it is based on promoting a particular way of using utterances as a 
key concept for understanding every other ways. This particular way namely consists in projecting concrete speeches into the aforementioned "game of giving and asking for reasons", that is to say into something they seem not always to be at first sight.

According to Brandom, such a particular reconstruction of the way meaning could be constituted is not to be understood as the only legitimate one. His aim is rather to show how it enhances the ability to explain the very nature of meaning (in contradistinction with Wittgenstein's “theoretical quietism", following Dummett 1978a's expression). ${ }^{2}$ The (theoretical) decision on which inferentialism is based is such that admitting its legitimacy depends on taking it over, i.e. on projecting oneself into the space which comes to be instituted by it. In other words, a factual choice comes before theorizing and then dilutes itself in the objectivist normative view on meaning that it has been instituting.

As a result, no subjective norm of meaning may ever be sustained, even though subjective (but as such "misleading") uses make the most part of real speeches. Indeed, new conceptuality may arise from a particular stance, but it would become graspable only if strategical inferential paths are cleared from the chaos of the awkward attempts through which concrete speeches mostly collapse. The institution of meaning through common regulation depends on locating any claim to meaning within a common game of giving and asking for reason. This game is not thought of as being anchored in a particular form of life, but rather in the very fact of the (provisional) plurality of forms of life, as naturally tending to communality and unity. One's particular refusal to submit one's own claim to meaning to a common regulation device may represent a particular stance, but it could never rely to a fully understandable meaning articulation, because it would always hit boundaries depending on arbitrary choices that another speaker might not be willing to take over. In this view, meaning should always be communicable and communicability should be itself reduced to argumentative defensibility.

But such an equation may not be completely necessary; the choice of a normative system might be preferably seen as not being repressed out of the frame of any argumentative stance, as we will see in the next section, but rather expressed as a constructive compound of it. ${ }^{3}$ The question is whether a subjectively defined frame of speech has necessarily to be doomed to semantic insignificance when it refuses its own dilution in public assessment?

\footnotetext{
${ }^{26}$ The idea is to show what kind of understanding and explanatory power one gets from talking this way [i.e., from the inferentialist sight], rather than to argue that one is somehow rationally obliged to talk this way." (Brandom 1994, xii). Now one may wonder whether it really makes a difference: if one convincingly shows that the adoption of this sight actually increases the explanatory power, than refusing it will represent an irresponsible stance.

${ }^{3}$ Brandom acknowledges a decisional compound in adopting the inferentialist framework, but once it is adopted, then one is committed to saying that any meaning is ultimately to be thought of as depending on the way it contributes to winning in the game of giving and asking for reason. Any stance that makes a speaker fail in this game must ultimately fade out as a claim to meaningfulness. In this extent, meaning only counts from a strategical sight, as we will see below.
} 
On predicator rules and indexicality

Clément Lion

\section{The program of building an Ortho-language (Orthosprache); differences with the program of Inferentialism}

As it has been initially formulated Kamlah and Lorenzen (1996) and Lorenzen and Schwemmer (1975), the program of building an Orthosprache (or "Ortho-Language") consists in reconstructing, step by step and from the scratch, the language of science by anchoring any meaningful sort of expression in a context of use, whose description requires only very elementary forms of articulations. It leads also to distinguishing sorts of words, so that anyone is enabled to make each part of an utterance associated to a teachable operation such that any complex statement holds as the result of a constructive path through which an elementary operation is developed step by step into a complexer one. Thus, no gap remains that would hinder a full mutual understanding. A predicator rule represents a means to make fully explicit the operative bases on which a predicator is to be defined, starting from a broader one and specifying its own way of operating.

In despite of similarities, Brandom's inferentialist take on meaning and Lorenzen's one diverge on a crucial point. While the former represents a theoretical option, aiming at giving an account of what meaning generally consists in (while conceding that, eventually, other explaining options are possible), the latter is based on acknowledging a factual discrepancy between many ways discourses are articulated as meaningful, so that building an Ortholanguage represents a task to be done, if one wants to unify scientific community. In other words, this Ortho- language must not be thought of as a theoretical means to make explicit what remains implicit when people scope at mutual understanding, but rather as a practical undertaking, intended to create the concrete conditions for building a unified community of speakers: usual ways of speaking are not essentially submitted to predicator rules! In Brandom's view, a universal norm of meaning is supplied through the device of argumentative praxis; in Lorenzen's view, such an universal norm is not given, but should be artificially created. It thus means that the way meaning is actually constituted is much more dependent on factual contexts of use in Lorenzen's view than in Brandom's. Even the very project of building an Ortho-Language depends on an historical context in which the discrepancy of uses sterilizes most of the philosophical investigations, insofar as it makes every theoretical product relative to a particular school, isolated from every others (Kamlah and Lorenzen 1996, 1). ${ }^{4}$

The Ortho-Language that Lorenzen was aiming at, as it is to be especially deployed through predicator rules in association with situations of teaching and learning, must be considered as an artificial device ${ }^{5}$ local discourses, essentially based on particular

\footnotetext{
${ }^{4}$ In the Logische Propädeutik, the concepts that express themselves in the natural language are not submitted to predicator rules, but rather to contextual uses, such that plasticity is one of their most essential features. It does not preclude however their own meaningfulness, inasmuch as they contribute to the opening of a world. In natural language, there is no necessity to go beyond this opening in order to deploy meaningful stances through language. Language must not necessarily be Ortho-Language.

${ }^{5}$ It is not the same as artificially identifying meaning to inferential relations: in one case, we have a theo-
} 
empragmatical anchorages, still belong to the domain of sense, in Lorenzen's view. By contrast, from an inferentialist sight, the set of the inferential relations according to which any sentence deploys its genuine meaning, must be conceived as an ideal norm of correctness, not depending on any decision taken by concrete speakers. At most, it is the adoption of the inferentialist framework, as a good theoretical device, challenging other possible ones, which may be eventually reported to a decision, but in such a way that it should ultimately be argued for in the game of giving and asking for reasons. In case this device reveals itself as the better one on the long run, there is no reason to accept that any meaning could be constituted out of such a common space of assessment.

\section{On two ways of rejecting incommunicability}

The very idea of building an Orthosprache is deeply connected with the rejection of any call to privacy in the constitution of a rational discourse, especially when dealing with sciences and mathematics. However, it seems not to be equivalent to saying that, in Lorenzen's view meaning itself should preclude privacy. It is rather the case that every day speeches are anchored in concrete situations, depending on inexpressible factual parameters, that are irreducible to any abstract device on which one could base to make them universally accessible. Any one finds himself within a determinate language whose meaning cannot be, as logicians tend to claim, abstracted from its historical situation, without falling into vagueness. In fact, when located in this situational anchoring, "vagueness" holds as a positive feature, that Kamlah and Lorenzen rather call "plasticity" (Kamlah and Lorenzen 1996, 65).

This is an important point to be made if one considers the way Lorenzen speaks of Brouwer's challenge to classical logic. In Logik und Agon, he describes it in term of a situation such that, suddenly, a group of people sees one of the most deeply anchored principles of logic, namely the excluded-middle, as unreliable (Lorenzen and Lorenz 1978, 2 ). This sudden arising of a mathematical practice finds its own distinctive expression in refusing to endorse the kind of (formal) inferential commitments, that have been traditionally formalized by logicians. It breaks accordingly the bridge between these "deviant" mathematicians and the community of those who are sticking to classical forms of reasoning. Even though this new mathematical practice have, at least provisionally, less demonstrative power than the usual one, one cannot assume that the utterances that are anchored in it must be denounced as meaningless. It is rather the case that a new stance has arisen through intuitionism, associated to the claim of its own irreducibility to the space of assessment of mathematical truth which were holding until then and which is based on the idea of a truth in itself. Such a break off was carried out through Brouwer's singular and unconventional voice. It has been given, to that extent, a philosophical basis

retical artifice, in the other case an institutional one, insofar as it puts a practical program on the table, that could easily be transformed into a political one. 
by Becker $(1927,636)$, to whom intuitionism represents a decisive step towards the acknowledgement of "facticity" within mathematics, contrarily to formalism, that ignores it. Becker's sight is indeed based on an Heideggerian conceptuality, yet such that the concerns with "authenticity" are now related, as it is not the case by Heidegger, to mathematical activity. Accordingly, one of the most controversial devices, namely the "free choice sequences", by which Brouwer attempted to give an account of what continuity is, expresses now, in Becker's mind, one of the most authentic mathematical construct (even though it tends, precisely because of its authenticity, to contradicts its own mathematical/ formal essence) (Becker 1927, 674). Accordingly logic, even though defined as a system of rules no justification should be asked for - because it allegedly delivers the basic material that anyone needs in order to supply any sort of justification - cannot hold any more as an impassable universal medium, out of which no meaningful discourse can ever be articulated. Formalist discourses, though consistent, miss their own factual anchoring in decisional parameters - dealing with time and historicity in Becker's perspective that they tend to forget.

In Lorenzen's view, logic must not be seen as a universal normative frame prefiguring every possible meaningful utterance. In league with Becker, he rather sees it as a device to which a function must be assigned in relation to the aim it is intended to serve. For both of them, purely formal logic is a way to flew away from facticity towards a normative stance, that enables one to push away its own (constructive) responsibility. However, Lorenzen clearly diverges from Becker when formulating the program of building an Ortho-Language. Even though meaning is not to be regulated through an allegedly universal abstract system of more or less broaden rules, the dialogue between different meaningful positions should regulates itself in such a way that a collaborative (re-)construction of a common system of rules holds, for any local speaker, as a possible factual choice, made from within his own local realm. Accordingly, the rejection of incommunicable features out of the domain of sense holds here as a practical commitment towards a dialogically regulated common frame whose construction depends on each speaker taking over the same type of commitment, in order to carry out a common basis for future constructions, but also on each speaker showing what eventually prevents him from adhering to this basis.

This way is to be carefully distinguished from the one that stands at the basis of Brandom's inferentialism and that was already expressed by Dummett:

To suppose that there is an ingredient of meaning which transcends the use that is made of that which carries the meaning is to suppose that someone might have learned all that is directly relevant when the language of a mathematical theory is taught to him, and might then behave in every way like someone who understood that language, and yet not actually understand it, or understand it only incorrectly. (Dummett 1978b, 217-218) 
On predicator rules and indexicality

Clément Lion

It is the very same idea that is expressed by Brandom, in a broadest sense, when saying that

[...] only what plays a suitable role in essentially social, indeed linguistic, discursive deontic scorekeeping practices should count as conceptually contentful in the fundamental sense. $(1994,608)$

That purely private compounds have to be rejected out of the domain of meaning is not to be understood, as it is the case by Lorenzen, in terms of a constructive decision, but rather in terms of a semantic impossibility, related to an objectivist view on what semantic is to be. It is ultimately based on the idea that no discursive commitment may ever be taken by a speaker without ascribing to other speakers the ability to assess whether it will have been correctly fulfilled (which depends on knowing unambiguously which inferential relations apply). The existence of a common normative frame of assessment is accordingly a necessary presupposition of any claim to meaning: this existence does not depend on any decision; it plays the role of a transcendental condition of meaning.

In Lorenzen's view, no such presupposition should be made without indicating how a constructive path towards it will be defined. Therefore, the decision of rejecting incommunicability out of the space of meaningful utterances cannot produce anything more than an essentially provisional common stance, which will always be threatened by the possible arising of new diverging practices disturbing mutual understanding in its most uncontroversial anchoring. If the Ortho-Language aims at rendering any articulation of scientific language in a dialogically constructive way, then it must give a place to meaning creation, as it may consist in destabilizing any fixed constructive articulation without necessarily destabilizing the accorded syntax. Accordingly, there must be a place for sense shifting, even when sense is decidedly located on a common constructive basis. ${ }^{6}$

\footnotetext{
${ }^{6}$ This is a point that is been investigated into by Schneider (1999) and Schneider (2014). While arguing in league with Wittgenstein that the program of unifying syntax and semantics within a systematic theory of meaning, defined in terms of rules that must regulate any type of linguistic use, is doomed to failure, Schneider refuses to endorse a "dismissive quietism", which would consist in sterilizing from the scratch any program of systematizing meaning. His claim is that language has a "systematic side", making its use similar to calculating by following rules, but it is such that it gets its own meaningfulness through another side, requiring "imagination". While no formalization will ever enables one to get through all possible meanings an utterance may have, because "grammatical forms are continually projected into new fields of activities" (Schneider 2014, 170) it represents however a key-device, without which no mastering of a language will ever be possible to acquire. Additionally, Schneider (1999, 472-493) argues that the program of building an Ortho-Language by anchoring every compounds of meaning in a typical situation, which makes it unambiguously teachable, cannot avoid a diverging of syntax and semantic to arise, due to the essential variability of the ways of acting that may be embedded into one and the same syntactic form of presentation.
} 
On predicator rules and indexicality

Clément Lion

\section{Can a privately deviant use of a given predicate be communicable?}

In order to explain what we have here in mind, we may take an example. Let us assume that an expert in a domain, for instance a skateboarder, tries to teach how to make a particular trick to a beginner. While saying "you must pop your deck this way", he shows exactly what he means and repeats the move several times until the beginner identifies precisely the relevant compounds of the move. Let us assume that the latter is now able to identify when himself, or anyone else, is rightly doing the move. It seems obvious that there will certainly remain ingredients, transcending the inferential uses of the expression "I pop my deck", and however essential to the correct understanding of it. It is certainly the case, insofar as the trick at stake takes place in a determinate form of life, that consists in "being a skateboarder".

The same may certainly be said concerning mathematics, as it has been deeply observed by Le Roy (1930, 118-121). Deploying a Bergsonian stance on creativity within mathematical practice, Le Roy argues that without a "driving image" ("image motrice"), no definitional rule can ever succeed in realizing a content for operative thinking. No constructive path can ever be followed if no pre-discursive image drives it, while furnishing more than what can ever be made explicit, namely the principle of a continuous constructive move, which also essentially cannot be made explicit, because analysing it is tantamount decomposing its continuity into separate moves. Mathematical educators should, Le Roy says, accordingly feed their pupils with something that is usually totally neglected, namely the "imaginative vitality". It is now certainly the case that such a Bergsonian conceptuality is burdened by a representationalist stance on meaning, as broadly denounced by Brandom (2000, 45-47): it presupposes an immediate access to an ineffable mental content, i.e. a private ingredient mysteriously enshrouding the use that an individual makes of mathematical symbols. It would certainly fall under the aforementioned Dummett's attack on allegedly private compounds of meaning. Our aim here is certainly not to contest the well-foundedness of such an attack. There is no doubt that it makes no sense to assume an absolutely private ingredient which would be nonetheless essential to mathematical understanding. The point is not yet exactly such, because Le Roy puts specifically the emphasis on the problem of transmitting this imaginative vitality: it presupposes thus an acknowledgement of its ability to take place within a common space of activity, eventually according to (at least informal) rules of interaction.

Brouwer was certainly deeply concerned with such a kind of matters, for instance when reporting his meeting of G. Mannoury:

As happens so often, I began my academic studies as it were, with a leap in the dark. After two or three years, however full of admiration for my teachers, I still could see the figure of the mathematician only as a servant of natural science or as a collector of truths: - truth fascinating by their immovability, but horrifying by their lifelessness like stones from barren mountains of disconsolate infinity. And as far as I could see there was room in the mathematical field for talent and devotion, 
but not for vocation and inspiration. Filled with impatient desire for insight into the essence of the branch of work of my choice, and wanting to decide whether to stay or go, I began to attend the meetings of the Amsterdam Mathematical Society. There I saw a man apparently not much older than myself, who after lectures of the most diverse character debated with unselfconscious mastery and well-nigh playful repartee, sometimes elucidating the subject concerned in such a special way of his own that straight away I was captivated. I had the sensation that, for his mathematical thinking, this man had access to sources still concealed to me or had a deeper consciousness of the significance of mathematical thought than the majority of mathematicians. [His papers] had the same easy and sparkling style which was characteristic of his speech and, when I had succeeded, not without difficulty, in understanding them, an unknown mood of joyful satisfaction possessed me, gradually passing into the realization that mathematics had acquired a new character to me. For the undertone of Mannoury's argument had not whispered: "Behold, some new acquisitions for our museum of immovable truths", but something like this: "Look what I have built for you out of the structural elements of our thinking. - These are the harmonies I desire to realize. Surely they merit that desire? - This is the scheme of construction which guided me. - Behold the harmonies, neither desired nor surmised, which after the completion surprised and delighted me. - Behold the visions which the completed edifice suggests to us, whose realization may perhaps be attained by you or me one day." (Brouwer 1975, 474-475)

One is confronted here with private ingredients of meaning —or better said "of significance" whose privacy should not be considered, however, as an absolute feature. They represent, so to say, a communicable privacy, whose communicability depends on parameters that do not let themselves easily embed into a well-defined situation of teaching and learning, because they depend on blurred kinaesthetic wholes, whose communality can very hardly be willingly constructed.

Let us call this type of use "privately deviant", because the private compound at stake is based on very small deviations from observable rightness, such that it lets itself hardly reach by discursive reports. These semantic deviations might be, in fact, compared with the very structure of the continuum, as thought of within Brouwer's mathematical intuitionism (Brouwer 1928, 4). If one takes into account the distinctive feature of the free choice sequences, namely their essential openness to further determination through a potentially infinite process of choice, then their being different is not equivalent to being apart one from another. Similarly, a particular use of mathematical language might be enshrouded by a "whispering undertone", making no explicitly reportable difference, while opening a space of play within which meaning, as regulated by use, would let itself index on unforeseeable differences, that reveal themselves in response to accurate requests, prescribed by no explicit rule, but also not restricted by the rules at work. By referring to a such similarity between a privately deviant compound of meaning and the open struc- 
ture of a free choice sequence, we may call semantic continuum the domain of analysis that an extended theory of meaning should investigate into, when aiming at rendering the dynamic features of meaning, that look like Mannoury's "whispering undertone".

The question is now: how to embed infintely proceeding sequences within dialogues in order to structure such a semantic domain of analysis, in such a way that a bridge can be built between meaning, as understood in this extended way, and truth, which any mathematical practice, even in Brouwer's mind, will always be aiming at?

\section{On the play level as a key device to make sense of what stands beyond the reach of Inferentialism}

We shall present here, in a purely programmatic way, a possible use of the crucial distinction, initially pointed out by Kuno Lorenz, within the framework of dialogical constructivism, between the play - and the strategic - levels (Lorenz 2010). It is important to point out that it represents certainly a continuation of Lorenzen's own sights, even though the emphasis is now differently distributed.

Let us recall that the kernel of the dialogical view on semantics consists in the idea that the meaning of an utterance is given by the way a justification process can be supplied through the execution of a finite dialogue starting from it, according to determinate interaction rules, acknowledged as such by a Proponent (P), who defends it, and an Opponent (O), who challenges it. No basis for justification has to be looked for outside the dialogue itself. No matter which private content one locates behind an assertion, the only relevant point is that by making this assertion, he entitles his interlocutor to tackle it according to the rules (which are at least of two sorts: particle rules, which are player-dependent and structural rules, which takes the nature of the player into account).

Now, the play - and the strategic - levels correspond to different (but complementary) sights on dialogues. From the first perspective, dialogues are executional processes, depending on factual choices that are made by concrete players. To that extent, the fact that $\mathrm{P}$ wins a dialogue cannot hold as a proof that his claim is true, because it may depends on O's (bad) choices. In order to make sense of what truth is, on must step into the second perspective, which depends not any more on the players' factual choices. In Lorenz's words:

[...] it is useful to observe that win and loss of a dialogue about a given proposition will in general depend upon an individual play of the game and will not be a function of the proposition alone. But the strategies of either player of the game are invariant against the choice of arguments of the other player. Hence, a proposition A shall be called 'true', iff there is a winning strategy for A; this means that the player who is asserting $\mathrm{A}$ - the proponent $\mathrm{P}$ - will be able to win a dialogue on

A independently of the choice of arguments of the opponent O. (Lorenz 2010, 11) 
We shall observe now that Brandom's inferentialist take on meaning corresponds to a strategic reading of dialogues, because it is based on stating the very existence of inferential relations, whose normative feature is not thought of as depending on the choices that are factually made by concrete interlocutors. But, as Rahman et al. $(2018,270)$ clearly points out:

not every sequence of moves in games of asking for reasons and providing them is necessarily inferential, only those plays leading to winning strategies are.

By sticking to the (universally) normative compound of meaning, Brandom's inferentialism is not any more than Dummett in position to extend the domain of semantic by incorporating into it, the aforementioned ingredient that transcends the normatively regulated use of any utterance, namely the one we called privately deviant. But now, if we go down into the play-level, at which factual choices are relevant, nothing prevents us any more from specifying rules that will regulate the factual use of ingredients, that may reveal themselves as totally irrelevant from a purely strategic point of view, while being however significant. These rules may take into account indexical compounds, if we are to take over Peirce's manner of calling the structure of a sign that relies to its object because of its being really affected by it (Peirce 1974, II. 248). Such ingredients as kinaesthetic wholes could accordingly take, as indexes or indexical processes, part of a common space of play, regulated by rules, not to be confused with objective norms in front of which any strictly subjective stance has ultimately to dilute itself. These indexical processes might be mathematically structured by using Brouwerian choice sequences as a form of presentation.

In other words, we suggest exploring, along the lines of Lorenz's crucial emphasis on the play level, what we called the semantic continuum, by mathematically approaching the rules through which singularities seek mutual understanding, even when they are assigned to formally determinate roles within strictly normative forms of communities. To that extent, we are here following a Brouwerian path, which is however clearly not solipsist, because it is constitutively dialogical. Indeed, the aim of building an Ortho-Language might incorporate its own immanent creative and metaphorical processing.

\section{Conclusion: a plea for indexing rules of inter- action on players and choices}

In his recent Oslo and Stockholm lectures, Per Martin-Löf has also taken a dialogical route towards a foundation of logic, and language in general, on ethics or deontology (Martin-Löf 2017a; Martin-Löf 2017b). In this perspective, the rules that regulate the use in which meaning consists should be called rules of interaction, rather than rules of inference. That a speaker be committed to assert $C^{\prime}$ because he has asserted $C$, depends ultimately of his being requested to by a hearer. Thus, in its most general form, the rule, which the meaning of an assertion is to be based on, could be schematically rendered in the following way: 


$$
\begin{aligned}
& \text { On predicator rules and indexicality } \\
& \text { Clément Lion } \\
& \frac{\vdash C \quad ? \vdash_{\text {may }} C}{\vdash_{\text {must }} C^{\prime}}
\end{aligned}
$$

It indicates that, while asserting $C$ a speaker implicitly gives to any hearer the right of requesting a justification for it, which represents accordingly a duty for himself.

Now, as observed by (Rahman et al. 2018, 293), it is not exactly the way a dialogician would render it. It would rather take the following form:

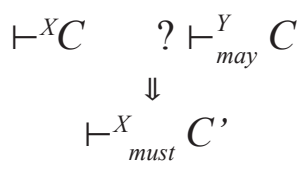

Firstly, instead of a bar, we should use an arrow, to remind Lorenzen's action-based background which is to be carefully distinguished from a purely inferential rule, as essentially disconnected from its operative anchoring. It is not only a question of notation: the bar relies to a norm that prescribes a duty, while the arrow rather indicates the possibility of interacting this way, which is accordingly a matter of choice. One can identify and apply such a scheme of interaction in the same way as one may learn how to knit or build a wall: in every case, the schemes at stake represent possible constructive path, and not categorical imperatives. Such a preference of dialogicians in choosing the arrow sign may find a justification in what we said before. The institution of a commonly regulated space of play essentially depends on the choice we make of constructing it and incorporating it into our forms of life. As such, a meaningful stance might aim at keeping out of this collective program.

It directly relies to what Rahman secondly points out, namely that this interaction rule would be, from the usual perspective of a dialogician, indexed on players ( $X$ and $Y$ ). We go now a little further on, by arguing that it must be indexed on players. Our argument relies on what we said previously, namely that no justification for constructing a common space of play can be given without observing fundamental divergences in singular ways of using language and of anchoring it in concrete situations. Martin-Löf's manner of symbolizing this fundamental rule of interaction misses the crucial point by staying disembodied from the very fact that forms of life are plural. In other words, he sticks, as a logician, to a formal view of what a social interaction is, namely that it is functionally definable and that the singular series of choices that institute each speaker as such brings nothing essential to the way functional relations are to be defined. By starting from a more radical point of view, we claim that these singular series of choices constitute the reason why something like propositional functionality in general emerges, namely as a constructive means to build a common space of play against the irreducible fact of incommunicability. 


$$
\text { On predicator rules and indexicality }
$$

Clément Lion

\section{References}

Becker, O. (1927). Mathematische Existenz. Tübingen: Niemeyer.

Brandom, R. B. (1994). Making it explicit. Reasoning, Representing and Discursive Commitments. Cambridge, Massachussets and London: Harvard University Press.

Brandom, R. B. (2000). Articulating Reasons. An introduction to Inferentialism. Cambridge, Massachussets and London: Harvard University Press.

Brouwer, L.E.J (1975). Collected Works. Ed. by Arend Heyting. Amsterdam: North-Holland.

Brouwer, L.E.J. (1928). Die Struktur des Kontinuum. Wien: Komitee zur Veranstaltung von Gastvorträgen ausländischer Gelehrter der exakten Wissenschaften.

Dummett, M. (1978a). Can Analytical Philosophy be Systematic, and ought it to be? In Truth and other Enigmas. Cambridge: Harvard University Press.

Dummett, M. (1978b). The Philosophical Basis of Intuitionistic Logic. In Truth and other Enigmas. Cambridge: Harvard University Press.

Kamlah, W., Lorenzen, P. (1996). Logische Propädeutik: Vorschule des vernünftigen Redens. Stuttgart, Weimar: Verlag J. B. Metzler.

Le Roy, E. (1930). La Pensée intuitive, II. Invention et Vérification. Paris: Boivin et Cie.

Lorenz, K. (2010). Logic, Language and Method. Berlin: De Gruyter.

Lorenzen, P., Lorenz, K. (1978). Dialogische Logik. Darmstadt, Germany: Wissenschaftliche Buchgesellschaft.

Lorenzen, P., Schwemmer, O. (1975). Konstruktive Logik, Ethik und Wissenschaftstheorie. Mannheim: Bibliographisches Institut A.G.

Martin-Löf, P. (2017a). Assertion and request. Lecture held at Oslo. Transcription by A. Klev. (no published work)

Martin-Löf, P. (2017b). Assertion and request. Lecture held at Stockholm. Transcription by A. Klev. (no published work)

Peirce, Ch. S. (1974). Collected papers of Charles Sanders Peirce. Ed. By Charles Hartshorne and Paul Weiss. Cambridge, Massachussets: The Belknap Press of Harvard University Press.

Rahman, Sh. et al. (2018). Immanent Reasoning or Equality in Action: A Plaidoyer for the Play Level(Logic, Argumentation \& Reasoning Series). Dordrecht: Springer International Publishing.

Schneider, H. J. (1999). Phantäsie und Kalkül. Über die Polarität von Handlung und Struktur in der Sprache. Frankfurt am Main: Suhrkamp. 
On predicator rules and indexicality

Clément Lion

Schneider, H. J. (2014). Wittgenstein's later Theory of Meaning. Trans. by Timothy Doyle and Daniel Smyth. Chichester, UK: Wiley Blackwell.

Wittgenstein, L. (1984). Philosophische Untersuchungen. Frankfurt am Main: Suhrkamp. 